\title{
Multimedia Enhancing Computer Based Training Modules for the Deaf, Supported by Case Study
}

\author{
Dr.Karim Q Hussein \\ Assist. Prof, Computer Science Dept./ Faculty of IT/ Al-Isra University \\ Amman - Jordan \\ E-mail: Karimzzm@ipu.edu.jo,karimzzm@yahoo.com \\ Dr. Ayman Nsour \\ Associated Professor, The Dean Academic Faculty of Information Technology \\ Al-Isra private University Amman - Jordan \\ E-mail: ayman@ipu.edu.jo
}

Received: February 27, 2011

Accepted: March 18, 2011

doi:10.5539/cis.v4n3p157

\begin{abstract}
Training aims at supporting student in developing specific physical skills. Therefore developer has to design effective modules for such purpose. He must develop his modules so that to represent/simulate all training activities via computer screen. According to our experience, such e-training modules are more complex as well as difficult than e-learning modules. Idea of research is to develop e-training modules (eTMs) for training skills to the Deaf \& Dumb (D\&D). Generic software has been developed to generate eTMs of any required training skills. Multimedia technique represents the core of simulation of training skills. Two projects have been developed, one for the teacher and the second for the student. The teacher is requested to enter the required training material into the teacher project. Effective pictures of training material would be entered by the teacher as well as the related clips of the training material are also added to the training modules particularly tools of training lesson and methodology of training lesson. Therefore the training material could be represented by text, pictures as well as clips. But all the oral/audio materials are to be translated into languages of D\&D like sign language and finger spelling. To realize effective training outcomes effective theories of learning/training must be depended in developing the e-training modules like perceptions theory (Landa) and sign learning (Tolman). To test the system, the training skills of paint brush software have been applied in developing the modules as case study. Visual Basic programming and its multimedia control components and technique are recommended to develop such eTMs. Thousands of sign language and alphabets finger spelling video clips are linked with the system
\end{abstract}

Keywords: eTMs, D\&D, Sign Language, Multimedia

\section{Objective of research}

This research aims at:

1) Developing (Analysis, Design and execute) a Generic Software system for authoring (eTMs) of any given training skills for the (D\&D).

2) Applying this system in generating experimental eTMs

3) Because the generated eTM are designed so as to be systematic and would realize maximized/effective training objectives as well as meaningful training, therefore the Generic software system must based upon effective learning/training theories like Tolman \& Linda theories

\section{Research methodology}

The diagram shown in Figure (1) shows the stages of the developing the Generic Software.

Now we shall explain each stage in brief:

\subsection{Analysis Stage:}

2.1.1 Perceptions theory(Landa(Landa, L. 1974)) is highly recommended to be used due to our surveying of 
theories of learning/training.

How could Linda theory be applied in analyzing the training material ?

The analysis aims at realizing the maximization of training outcomes

The training material is analyzed according to the theory of research as follows.

1- The main objective of the material is divided into independent sub-objectives.

2- Each sub-objective leads to certain activities (physical activities) to realize achievement of that sub-objective.

3- Each activity is to be done under certain conditions.. The conditions describe the past training skills and current experience of D\&D to accomplish the corresponding activity. Besides they describe the typical physical enjoinment of the training activity under process.

Figure (2) shows the analysis technique in the model.

2.1.2 Sign theory ( E.Tolman (Tolman, E.c. 1992)).

This learning theory is also called purposive behaviorism and is considered as a bridge between behaviorism and cognitive theories.

According to this theory, learning/training by organism is acquired through meaningfully pursuing of sign to a goal.

According to Tolman a new stimulus (the sign) becomes associated with already meaningful stimuli (the significant) through series of pairings.

Therefore it is highly recommended to apply this theory in methodology of training subject so that the eTM should strongly and effectively enhanced by signing activities to compensate the physical training activities in the real world

\subsection{Technical design and $S / W$ design}

The output of analytical stage leads to the input of technical design stage.

The following elements represent the factors of the technical design and software design for the eTMs.

1) Output analysis of the training material in the analysis stage

2) Training methodology like demonstration, project, printed material, etc.

3) Modes of communication with D\&D student like sign language, lip movement and finger spelling, multimedia is used to represent the media of communication.

4) eTMs methods like tutorial, simulation, etc

5) Preparing fun \& enjoyment material via eTM.

6) Preparing messages of feedback and reinforcement.

The table in Fig. 3 describes the mechanism of the technical design stage to develop eTMs for the D\&D.The table shown represents the technical design stage. It includes 4 fields. Each field represents a factor in technical design stage. Field 3 leads to the next stage.

\section{Developing the Generic Software}

The output of the above diagram leads to the block diagram of the Generic software. However this Generic software aims at generating any desired eTM of any training skills subject for the D\&D.We will select demonstration training method which is somewhat corresponding to the tutorial method in eLMs (e-learning modules).

The diagram shown in figure (4) shows the block diagram of the Generic software of the research.

The real print-screen print out figures $(5,6,7,8$ and 9$)$ represent samples of real run-out forms of the system, we shall display three forms for trainer projects. Also we shall display the corresponding forms in the student project for each of them.

Q) What is the multimedia technique used in translation words from text into sign language and finger spelling?

Components and modules of multimedia in Visual Basic programming have been used in developing this system. This coding technique and sources allow this system to generate amount of eTMs modules for the D\&D. The source has been linked with 3000 video cuts of sign language actions besides 58 pictures of alphabets finger 
spelling (American one hand spelling).

Fig.10 shows multimedia technique in translating objects from text into sign language and finger spelling.

\section{Applying the system}

As per the previous samples of real run-out forms in both trainer project(teacher) and student project we can prove that the system generates eTMs of any training skills for the D\&D successfully. As the physical activities represent the core of the training skills, Therefore, all the activities in the eTM should be enhanced effectively by multimedia technique so that video clips and finger spelling can describe the training lesson via visual information to the D\&D.

\section{Conclusion}

The authors summarized their conclusion as shown below:

1- The Generic software of developing eTMs can successfully generate any eTM for the D\&D of any required training skills. It can generate multiple eTMs of different training subjects.

2- The Generic software was developed systematically so that it based on two main training/learning theories , perceptions theory of Landa and sign learning of Tolman , therefore the generated eTMs by this Generic software are expected to realize the benefits of these theories which are:- maximization of training outcomes and meaningful training.

3- This Generic software was developed in sequential and integrated stages so that the output of any stage leads to the input of next stage. This systematic model of developing eTMs for the D\&D can cover the requirements of the trainer as well as the D\&D students. As the Generic software covers multiple modes of communications (finger spelling and sign language), therefore, it is expected that the generated eTMs satisfy the training requirements of all categories of the D\&D students.

4- This Generic software is enhanced with thousands of video clips and finger spelling multimedia. However this multimedia technique is aimed at translating all words from text into sing language and finger spelling besides describing the training skills in the student screen via pictures and motions.

Therefore we can say that multimedia can enhance eTMs effectively so that to compensate the audio/oral training material via the corresponding material in visual mode. Thus Multimedia supports the D\&D student in improving his own skills regarding the training subject.

\section{References}

Chandrasekaran, B. (1986). Generic Tasks for Knowledge-Based Reasoning: The Right Level of Abstraction for Knowledge Acquisition, IEEE Expert, 1, pp.23-30. 1986

Cooke-Plagwitz, Jessamine. (2007). Generic Software for Foreign Language Instruction: A Snapshot of Teachers' Approaches. [Online]

http://www.readingmatrix.com/conference/pp/proceedings2007/cooke_plagwitz.pdf

Available:

Grimshaw, Shirley. Authoring Environments for Intelligent Systems: ESRC Center for Research in Development, Instruction and Training. Computer - Supported Collaborative Learning. [Online] Available: http://www.phychology.nottingham.ac.uk/staff/com/c8clotnchapterpat

Hussein , Karim Q. (2000). The Role of Perceptions Theory in Developing Training Computer Models (Technical approach), Arabic Conference of Technical Education, Higher Vocational Center for Computer technology, Tripoli , Libya 26-28th FEB2000.

Hussein, Karim. Q. (2000). Development of an Evaluation Model for Instructional Computer Programs According to Technical Criteria, Arabic Conference of Technical Education, Higher Vocational Center for Computer technology, Tripoli, Libya 26-28th FEB2000.

Kaplan, Harriet \& Mahshie, James \& Moseley, Mary \& Singer, Beth \& Winston, Elzabeth. Design of Effective Media Materials and Technology for Deaf and Hard - of - Hearing Students. This document was prepared by National Center to Improve the Tools of Education, U.S. efface of Special Education Programs. [Online] Available: http://idea.uoregon.edu/ ncite/documents/techrep/tech01.html

Knowles, Lan. Teaching Deaf and Hearing Impaired Students: The University of Sheffield, Uk. [Online] Available: http://www.Shef.ac.UK/disability/teachin hearing/5-strategies.html

Landa, L. (1974). Algorithmization in Learning and Instruction, Englewood cliffs, NJ, Educational Technology publications, 1974. [Online] Available: http://www.wim.edu/users/mfill/Landa .htm 
Poobrasert, Onintra \& Mguine, Brain. (2005). Knowledge Engineering in Multimedia Design and Computer Assisted Learning for Special Needs Training: Effectiveness, The 9th World Multi-Conference on Systemic, Cybernetics and Informatics July 10-13, 2005 - Orlando, Florida, USA. [Online] Available: http://www.iiisci.org/sci2005/proceedingssci/vol8-2001.asp

Tolman, E.c. (1992). A new formula for behaviorism. Psychological Review, 1992. [Online] Available: http://psychclessic.yorku.ca/Tolman/forua.htm

Waston, Léonie. Multimedia: Enhancing Ability. [Online] Available: http://www.skillsforaccess.org.uk/articles,phd?id=152\#auther\#auther

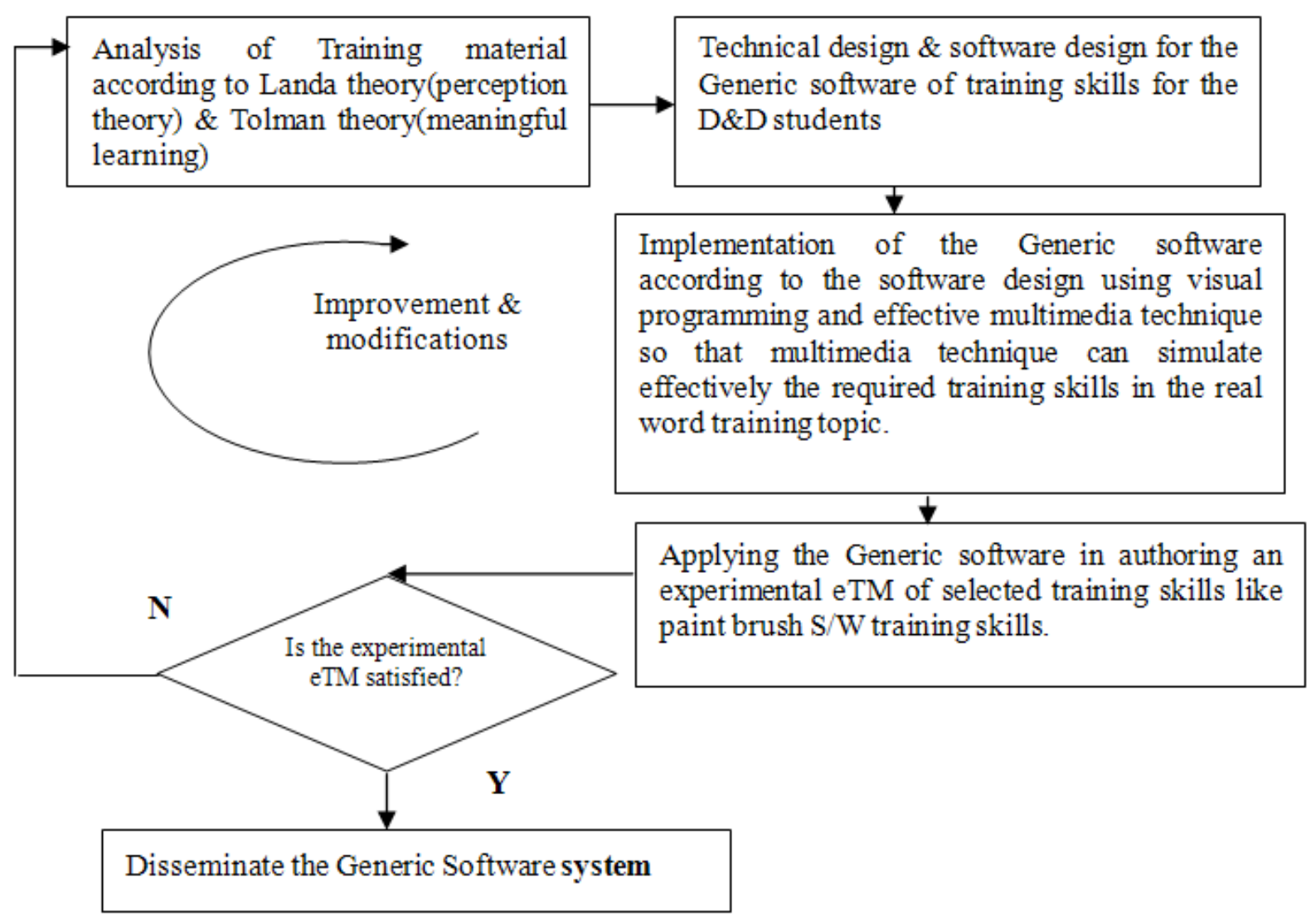

Figure 1. Block Diagram of Research Methodology

\begin{tabular}{|c|c|c|}
\hline Outcomes(Objectives) & Activities & Conditions \\
\hline Objective $1 \longrightarrow$ & Activity 1 & Condition 1 \\
\hline Objective 2 & Activity 2 & Condition 2 \\
\hline Objective 3 & Activity 3 & Condition 3 \\
\hline • & - & - \\
\hline . & - & - \\
\hline Objective $\mathrm{n} 1$ & Activity n2 & Condition $\mathrm{n} 3$ \\
\hline
\end{tabular}

Figure 2. Analysis Technique of The Training Lesson 


\begin{tabular}{|c|c|c|c|}
\hline $\begin{array}{c}1 \\
\text { Training } \\
\text { objective item } \\
\text { in technical } \\
\text { design }\end{array}$ & $\begin{array}{c}2 \\
\text { The Analysis } \\
\text { of content of } \\
\text { the training } \\
\text { objective }\end{array}$ & $\begin{array}{c}3 \\
\text { Select } \quad \text { and design of } \\
\mathrm{e}-\text { training Method }\end{array}$ & $\begin{array}{c}4 \\
\text { Mode of } \\
\text { communication } \\
\text { between computer and } \\
\text { D\&D Trainer }\end{array}$ \\
\hline $\begin{array}{l}\text { Item ( i ) } \\
\text { (objective } \mathrm{i} \text { in } \\
\text { the analytical } \\
\text { stage) } \\
\text { After finishing } \\
\text { of technical } \\
\text { design of item } \\
\text { ( i ), we repeat } \\
\text { all details to } \\
\text { design item ( } i \\
+1 \text { ) }\end{array}$ & $\begin{array}{l}\text { Rewrite } \\
\text { Activities and } \\
\text { Conditions with } \\
\text { renewed aspect, } \\
\text { so that the new } \\
\text { content } \\
\text { represents the } \\
\text { training } \\
\text { material which } \\
\text { would be } \\
\text { displayed on the } \\
\text { screen } \\
\text { computer for } \\
\text { D\&D trainer. } \\
\text { However all the } \\
\text { output on } \\
\text { screen must be } \\
\text { translated into } \\
\text { languages } \\
\text { suitable for } \\
\text { D\&D student } \\
\text { (finger spelling, } \\
\text { sign language, } \\
\text { lip movements, } \\
\text { etc). }\end{array}$ & $\begin{array}{l}\text { Select the e-training method } \\
\text { (tutorial, simulation, etc ) that supports the } \\
\text { the objective of eTMs of that lesson by D\&D student. } \\
\text { There must be a specific block diagram which describes } \\
\text { the mechanism of the e-training lesson and flow of } \\
\text { information via the e-lesson for tutorial method is depicted } \\
\text { below as an example. }\end{array}$ & $\begin{array}{l}\text { Three main modes of } \\
\text { communication would } \\
\text { be recommended by the } \\
\text { model : sign language, } \\
\text { finger spelling and lip } \\
\text { movement besides } \\
\text { normal text/picture } \\
\text { presentation and sound. }\end{array}$ \\
\hline
\end{tabular}

Figure 3. Table of Technical Design for the Generic Software of Items for D\&D Trainers 


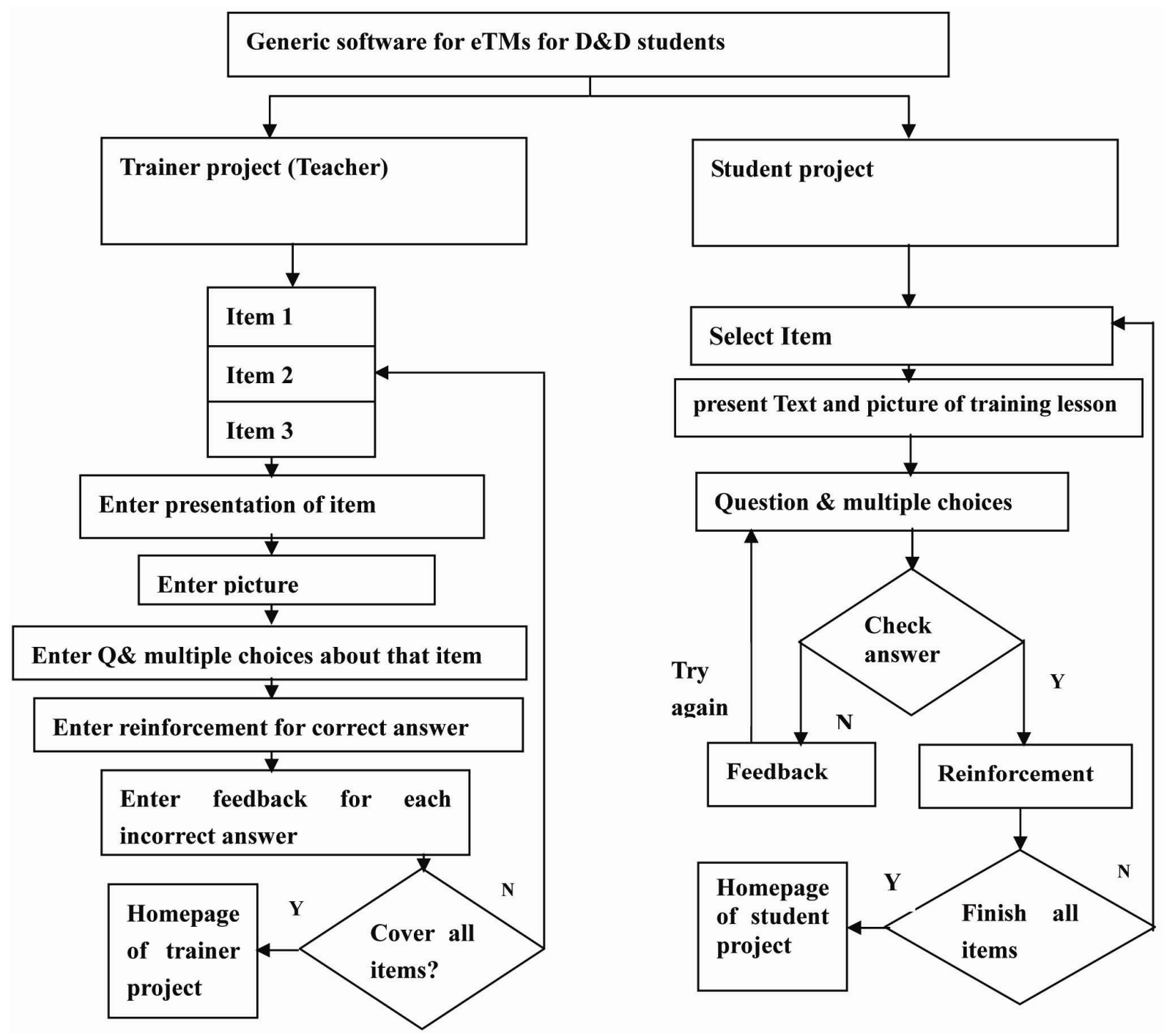

Figure 4. Block Diagram of Generic Software Which Generates eTMs for D\&D trainers 


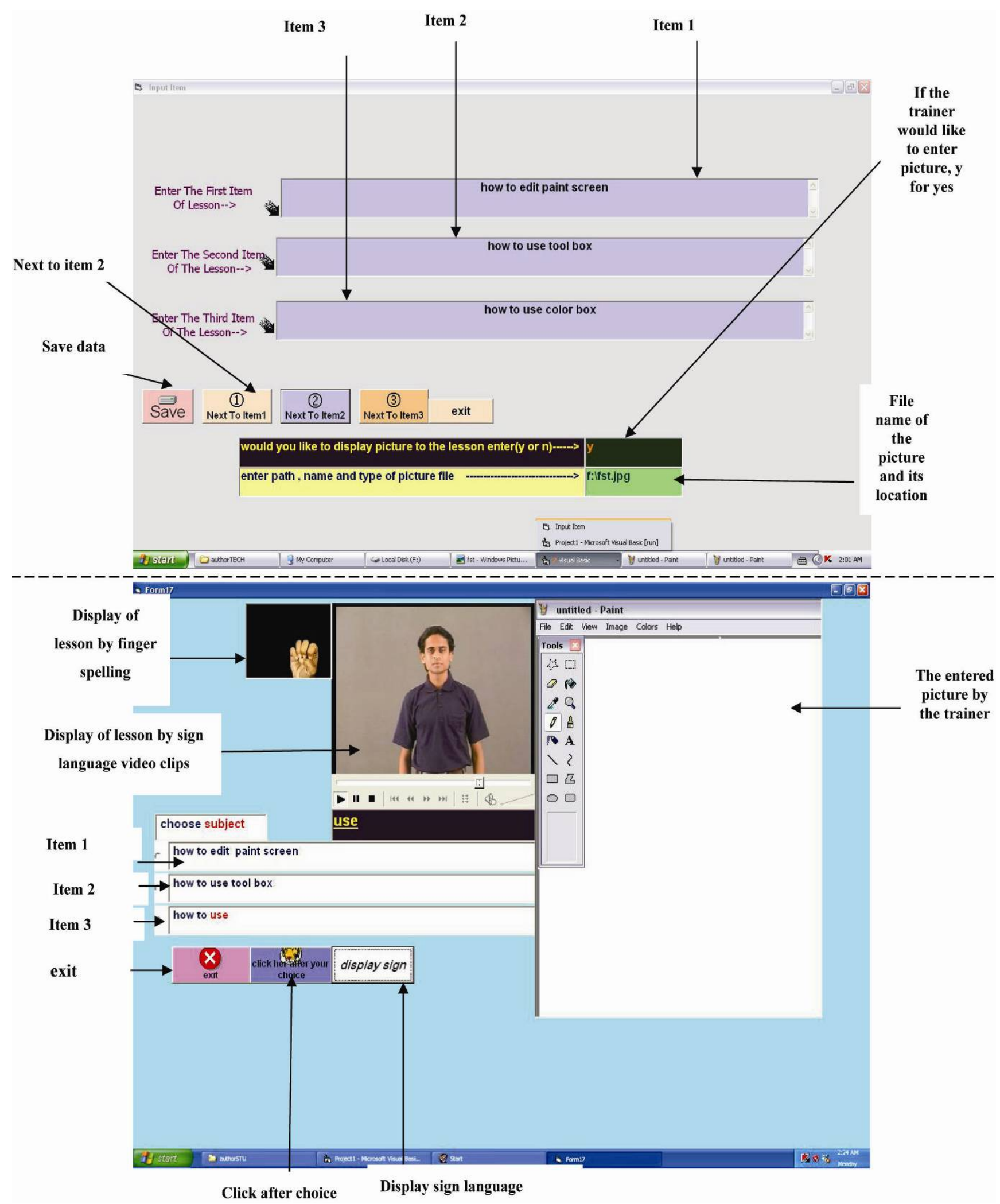

Figure 5. real run-out forms of experimental case study for topic of paint brush skills, form of trainer and corresponding form for the student, (items of eTM and corresponding picture of lesson) 


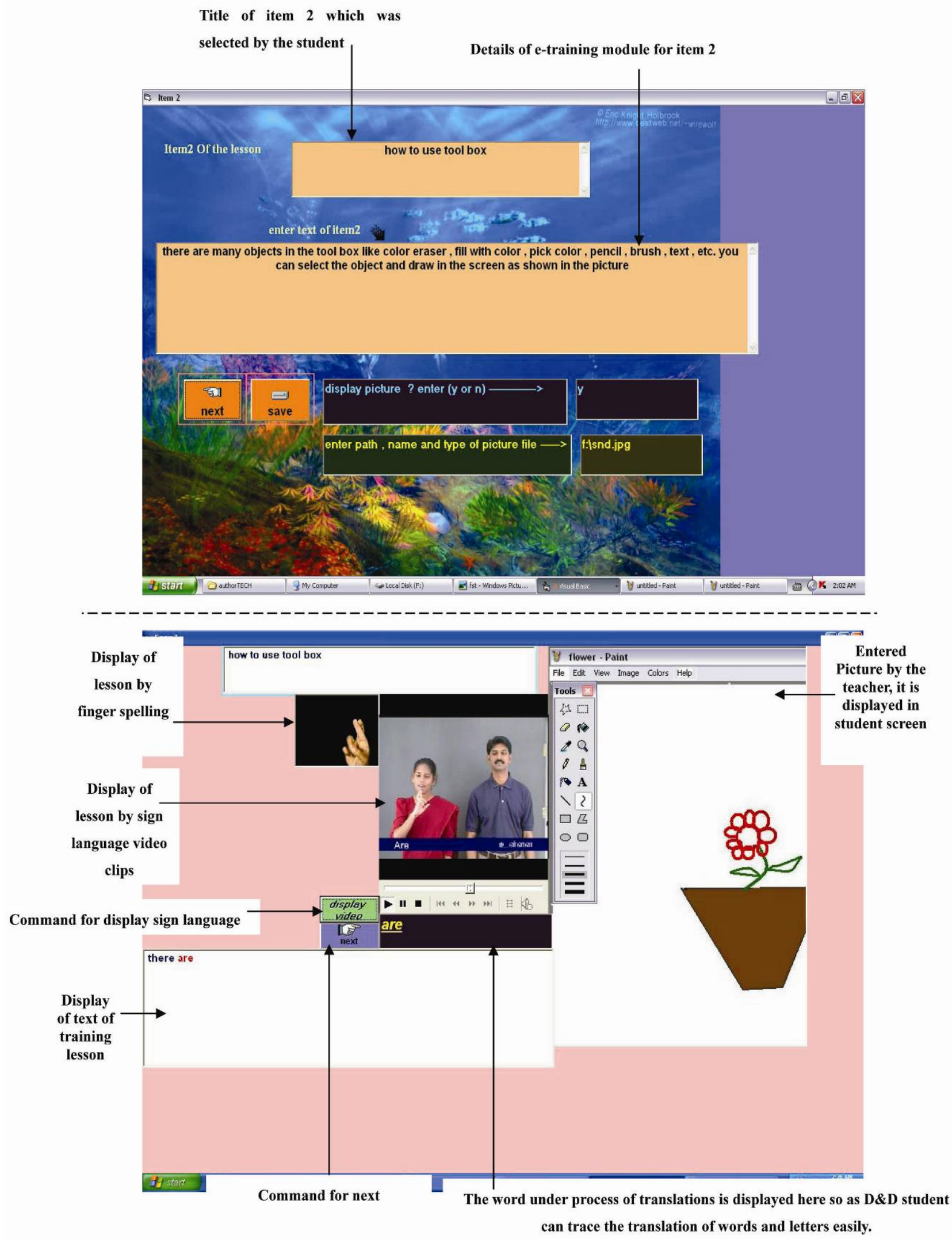

Figure 6. form of entry training material for trainer and student 


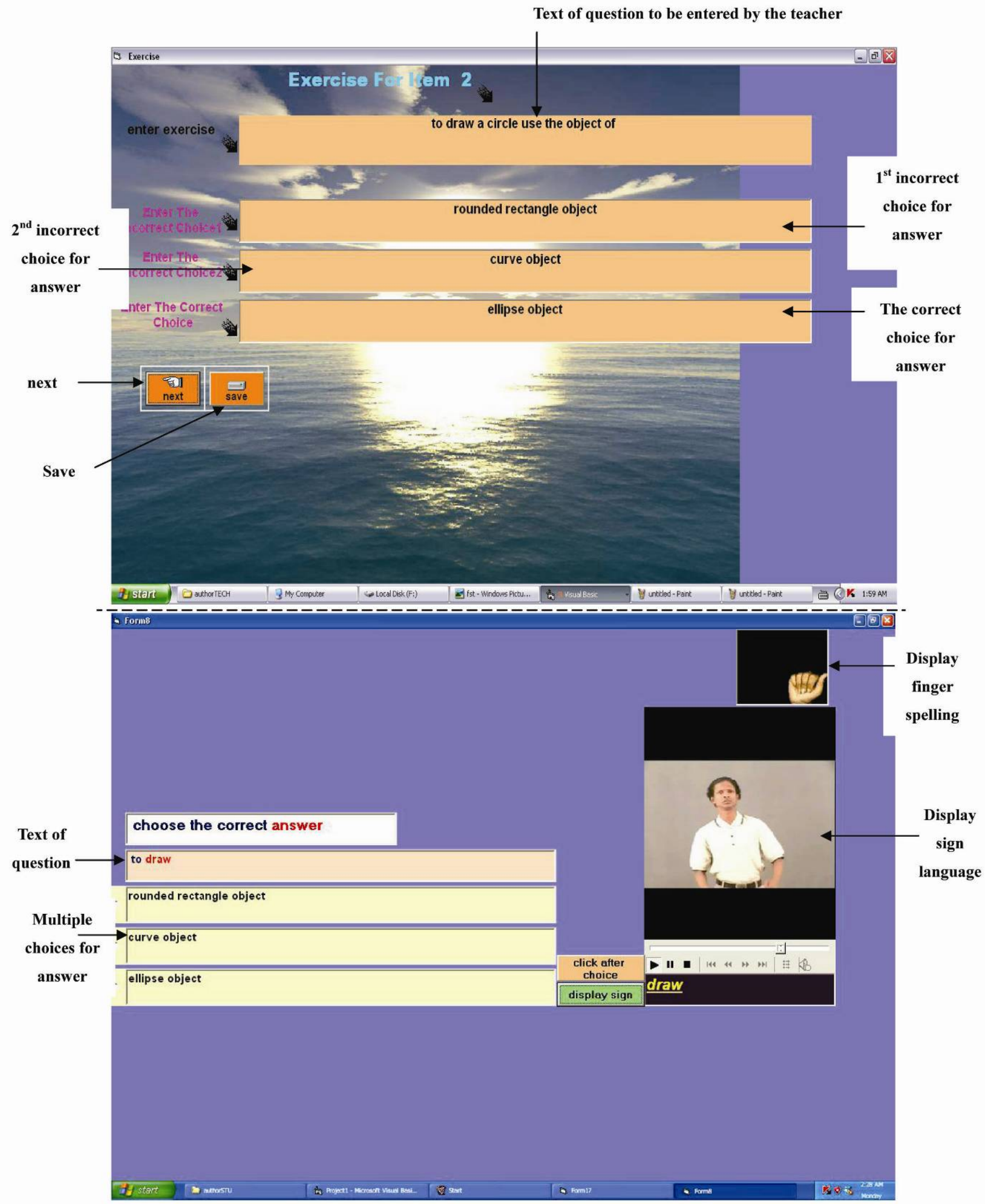

Figure 7. form of question and multiple choices for teacher project and its corresponding form in student project 


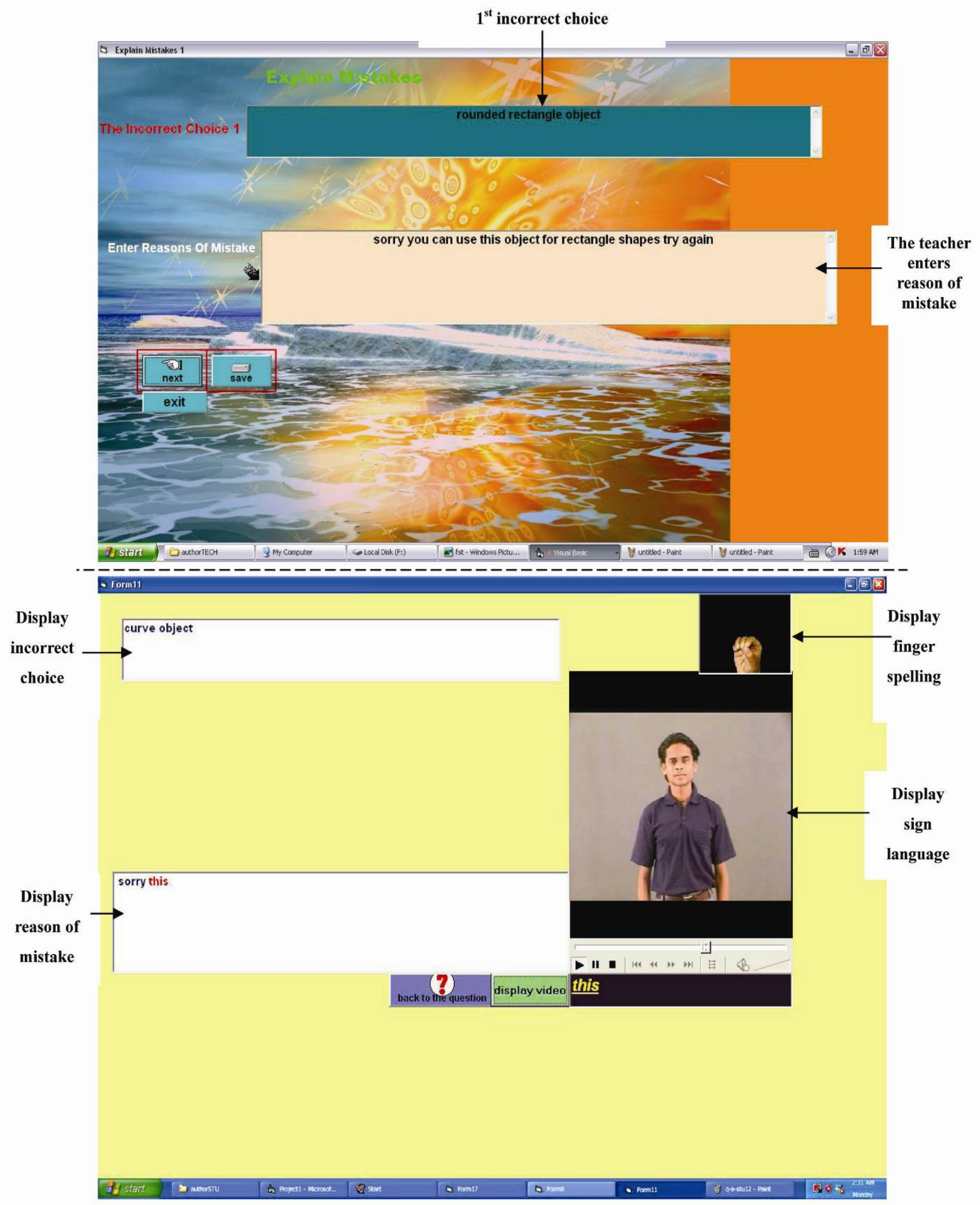

Figure 8. form of $1^{\text {st }}$ incorrect answer for teacher project and its corresponding form in student project 


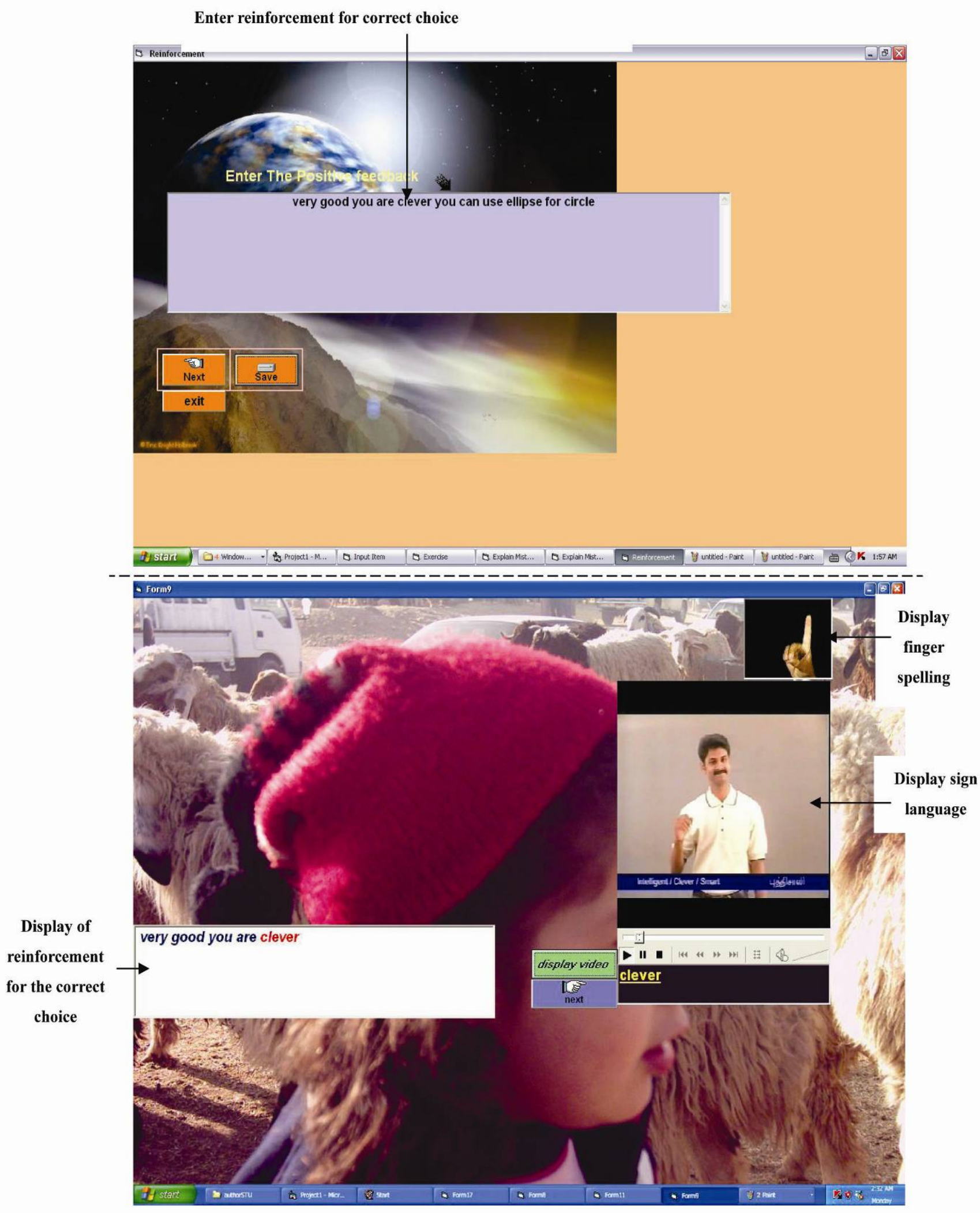

Figure 9. Student form of reinforcement in trainer project and its corresponding form in student project 


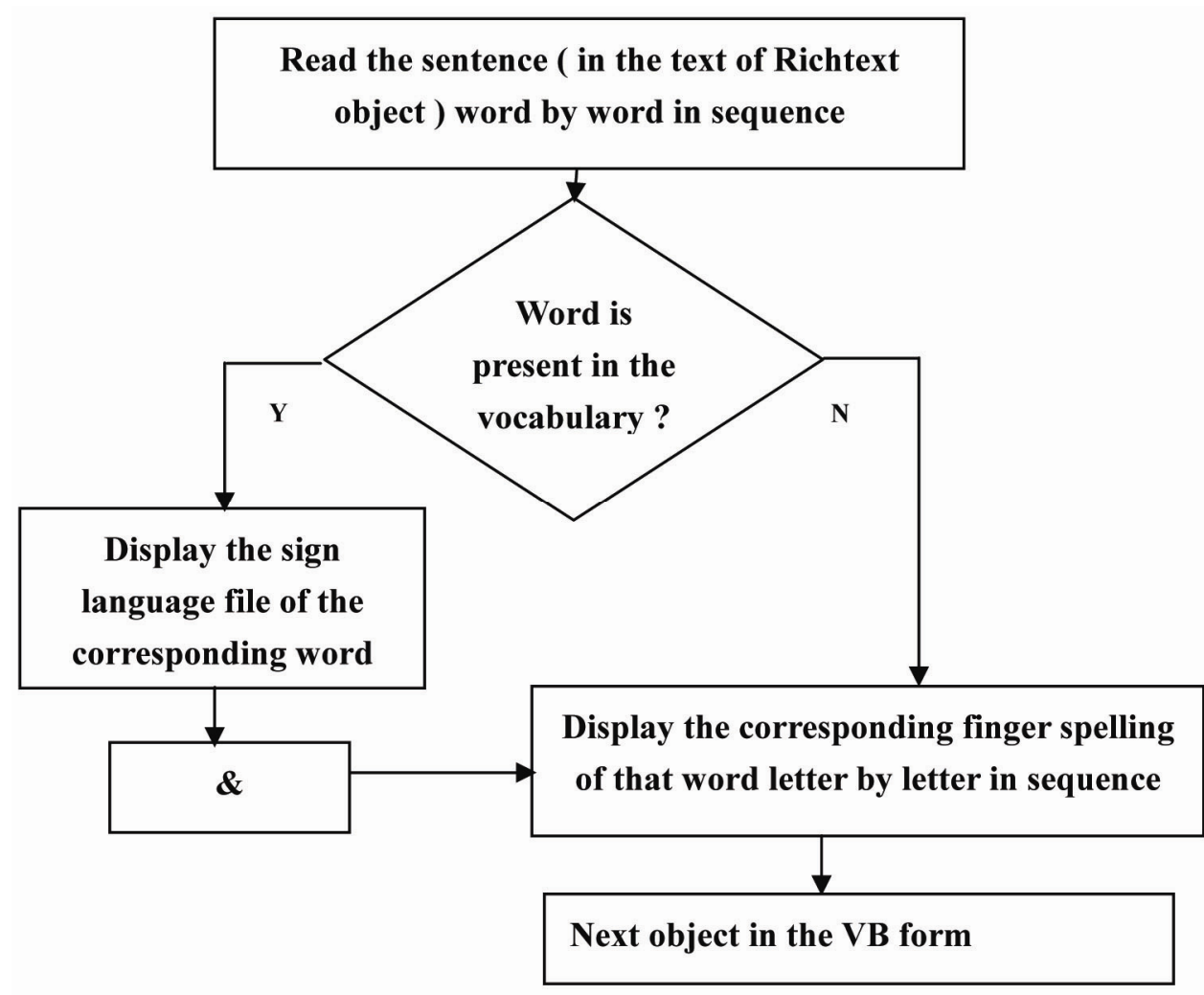

Figure 10. Technique of Displaying Multimedia Video Clips of Sign Language 